\title{
Les urnes du ciel
}

Pierre-Olivier Dittmar et Rodolphe Montet

\section{(2) OpenEdition}

Journals

Édition électronique

URL : https://journals.openedition.org/tc/6951

DOI : $10.4000 /$ tc. 6951

ISBN : 1952-420X

ISSN : 1952-420X

Éditeur

Éditions de l'EHESS

Édition imprimée

Date de publication : 19 juin 2013

Pagination : 224-225

ISBN : 978-2-7351-1637-9

ISSN : 0248-6016

Référence électronique

Pierre-Olivier Dittmar et Rodolphe Montet, « Les urnes du ciel », Techniques \& Culture [En ligne], 60

2013, mis en ligne le 19 juin 2016, consulté le 29 septembre 2022. URL : http://

journals.openedition.org/tc/6951 ; DOI : https://doi.org/10.4000/tc.6951 


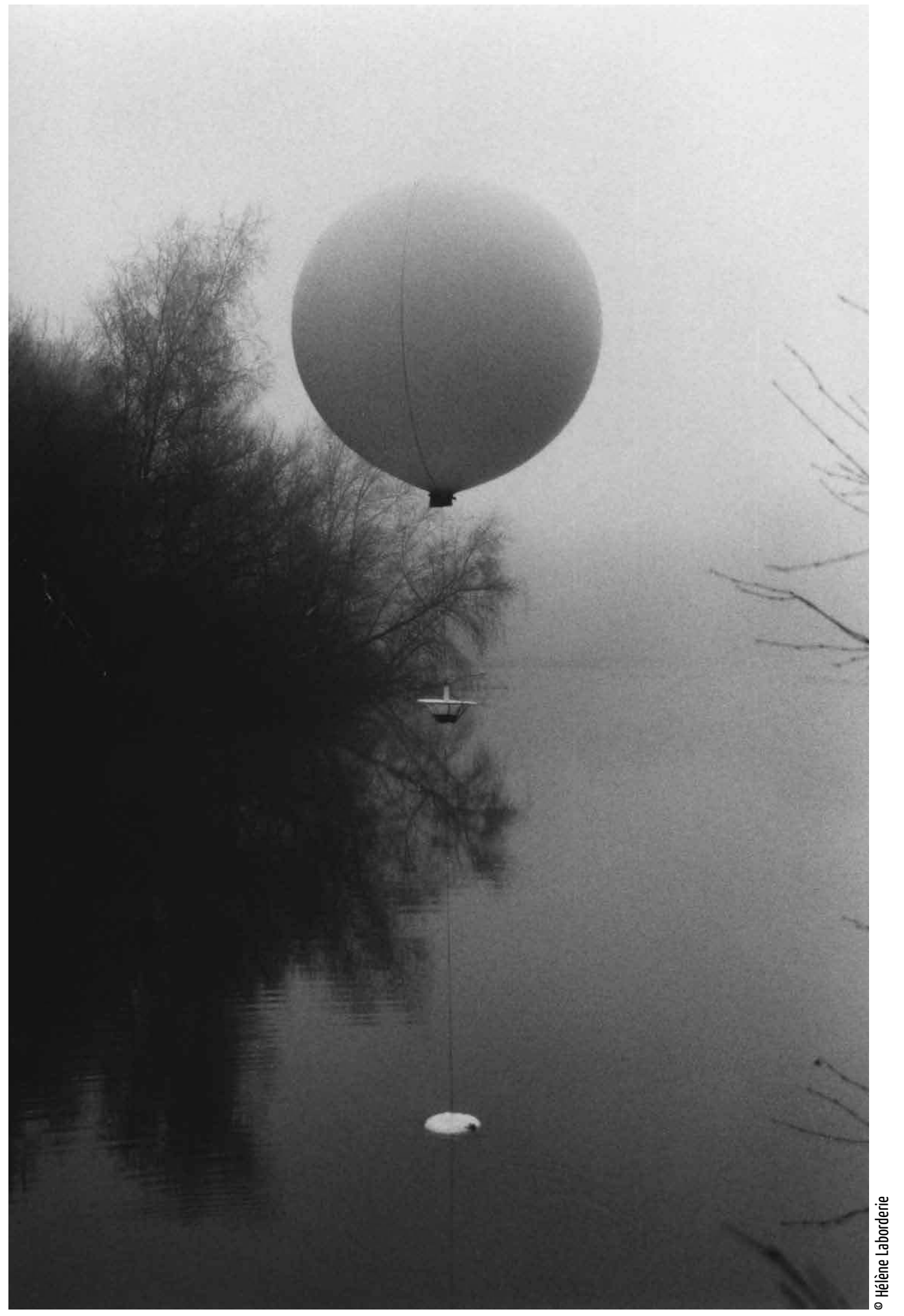


Pierre-Olivier Dittmar \& Rodolphe Montet

EHESS Paris

dittmar@ehess.fr

Artiste plasticien

\section{Le Cadavre en procès}

Techniques \& Culture 60, 2013/1 : 224-225

\section{LES URNES DU CIEL}

15 août 2004. Petit matin. Un ballon d'hélium s'élève au-dessus des collines, emportant avec lui une nacelle conique en tissu blanc. À mesure qu'elle prend de l'altitude, la sphère se dilate, mettant en tension de minuscules cordons, qui lentement retournent la nacelle, libérant dans l'atmosphère, au milieu des nuages, les cendres d'un être humain mort il y a peu. Avec ses urnes, Rodolphe Montet propose un rituel nouveau, aux importantes conséquences anthropologiques et esthétiques. Car il s'agit bien de donner une forme nouvelle à la mort, de l'arracher à toute la pesanteur romantique, pathétique que lui avait conférée la tradition occidentale. Évidence d'une proposition qui, par sa légèreté et sa délicatesse, rompt radicalement avec deux millénaires d'art funéraire.

Celui-ci a longtemps joué un rôle de premier plan dans l'art occidental, qu'il s'agisse de l'apparition du portrait ressemblant au $\mathrm{XIII}^{\mathrm{e}}$ siècle sur les gisants puis sur les transis, ou encore les véritables performances d'art total que représentent les funérailles entre la fin du $\mathrm{XV}^{\mathrm{e}}$ et le $\mathrm{XVII}^{\mathrm{e}}$ siècle. De fait, une large partie de l'art chrétien, jusque dans ses dimensions les plus monumentales (les basiliques), s'est érigée sur et autour de cadavres. « Les morts appellent les vivants » disait l'adage. C'est bien parce que l'image était réputée pouvoir rendre présents les absents qu'elle s'est développée de façon privilégiée dans le contexte funéraire (Belting 2001:184-185).

La crémation, lorsqu'elle est accompagnée d'une dispersion des cendres, s'oppose structurellement au tombeau, en ce qu'elle vise à faire disparaître toute trace matérielle durable du corps du défunt. De façon assez logique, bien qu'elle soit légale depuis 1889, et qu'elle concerne en France $30 \%$ des défunts, cette pratique n'a suscité presqueaucune production artistique spécifique.

Pour respecter ce désir de disparition, les urnes nouvelles de Rodolphe Montet ne proposent pas de lieu de mémoire, mais le support matériel d'un rituel à inventer. Ses nacelles transparentes laissent entrevoir les cendres que les urnes traditionnelles cachent, pour mieux mettre en scène leur disparition dans les airs.

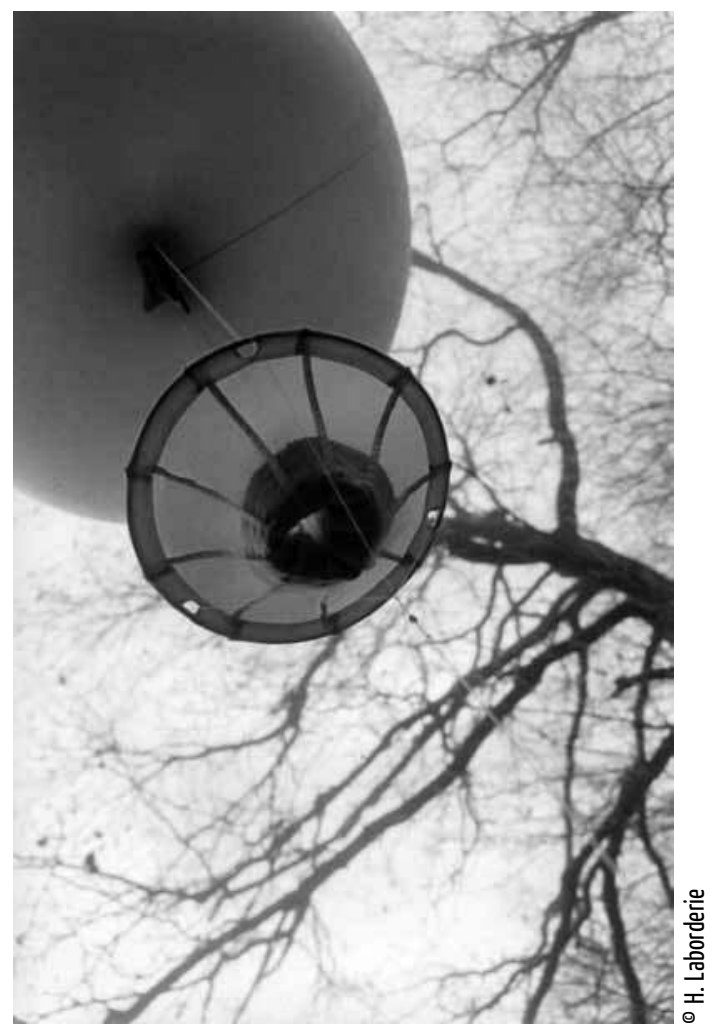

Belting, H. 2001 Pour une anthropologie de l'image. Paris : Gallimard. 